\title{
Design and Synthesis of an Indole-Estrogen Derivative
}

\author{
Figueroa-Valverde Lauro, ${ }^{1}$ Díaz-Cedillo Francisco, ${ }^{2}$ \\ Rosas-Nexticapa Marcela, ${ }^{3}$ Hau-Heredia Lenin, ${ }^{1}$ García-Cervera Elodia, ${ }^{1}$ \\ Pool-Gómez Eduardo, ${ }^{1}$ and Sarabia-Alcocer Betty ${ }^{4}$ \\ ${ }^{1}$ Laboratory of Pharmacochemistry, Faculty of Chemical Biological Sciences, University Autonomous of Campeche, \\ Avenida Agustín Melgar s/n, Colonia Buenavista, 24090 México, CAM, Mexico \\ ${ }^{2}$ Escuela Nacional de Ciencias Biológicas del Instituto Politécnico Nacional, Prol. Carpio y Plan de Ayala s/n, Colonia Santo Tomas, \\ 11340 México, DF, Mexico \\ ${ }^{3}$ Facultad de Nutrición, Universidad Veracruzana, Médicos y Odontologos s/n C.P. 91010, Unidad del Bosque Xalapa Veracruz, \\ México, Mexico \\ ${ }^{4}$ Faculty of Medicine, University Autonomous of Campeche, Avenida Patricio Trueba de Regil s/n, Colonia Lindavista, \\ 24090 México, CAM, Mexico
}

Correspondence should be addressed to Figueroa-Valverde Lauro; lauro_1999@yahoo.com

Received 24 July 2014; Revised 24 September 2014; Accepted 25 September 2014; Published 18 November 2014

Academic Editor: Andrea Penoni

Copyright (C) 2014 Figueroa-Valverde Lauro et al. This is an open access article distributed under the Creative Commons Attribution License, which permits unrestricted use, distribution, and reproduction in any medium, provided the original work is properly cited.

\begin{abstract}
There are several methods reported for synthesis of aromatic-condensed derivatives; nevertheless, expensive reagents and special conditions are required. Therefore, in this study, an indole-estrogen derivative (3-[4-(2-butyl-3-cyclohexylimino-4-piperidin1-yl-cyclobutylidencarbamoyl)]-phenoxy-NH-indolo $\left[2^{\prime}, 3^{\prime}: 17,16\right]$ estra-1,3,5(10)triene) was synthesized using some strategies. The structure of all compounds obtained was confirmed by spectroscopic and spectrometric methods. In conclusion, a facile procedure for the formation of an indole-estrogen derivative was developed in this study.
\end{abstract}

\section{Introduction}

Indole derivatives are a very important heterocyclic compounds which induced several biological activities [1, 2]. It is important to mention that there are several methods reported for synthesis of aromatic-condensed derivatives, for example, the synthesis of indole derivatives via palladiumcatalyzed heteroannulation of internal alkynes [3]. Other studies showed the synthesis of an indole derivative by reaction of $N$-aryl Amides with ethyl diazoacetate [4]. In addition, some indole derivatives were development using the palladium-catalyzed coupling of alkynes with iodoaniline derivatives [5]. Other data showed that ruthenium catalyzed synthesis of indole from $N$-substituted anilines and alkanolamines [6]. Also a study shows the synthesis of 2substituted indole derivatives from 2-ethynylanilines with tetrabutylammonium fluoride [7].
On the other hand, a series of indole-steroid derivatives have been developed, for example, the synthesis of $1^{\prime}$ methylindolo $\left(3^{\prime}, 2^{\prime}: 2,3\right)-2(5 \alpha)$-androsten-17-one by the reaction of $5 \alpha$-androstan-3,17-dione with 1-methyl-1-phenylhydrazine $[8,9]$. Other data indicate the preparation of $(\mathrm{Z})-16-$ (7-aza-1H-indol-1-yl) methylen-17-oxoandrost-5-en-3 $\beta$-yl acetate by the reaction of 17-chloro-16-formylandrosta-5,16dien-3-yl acetate with 7-azaindole under $\mathrm{N}_{2}$ atmosphere [10]. In addition, the synthesis of 17-indazole androstene derivative was prepared by the reaction of 17-chloro-16formylandrosta-5,16-dien-3 $\beta$-yl acetate with indazole [11]. Additionally, other studies show the synthesis of $1^{\prime} H-5 \alpha$ cholest-2-eno[3,2-b]indole using the Fisher reaction [12]. Recently, an indole-dihydrotestosterone derivative was synthesized by the reaction of dihydrotestosterone with phenylhydrazine using hydrochloric acid as catalyst [13]. All these experimental results show several procedures which 


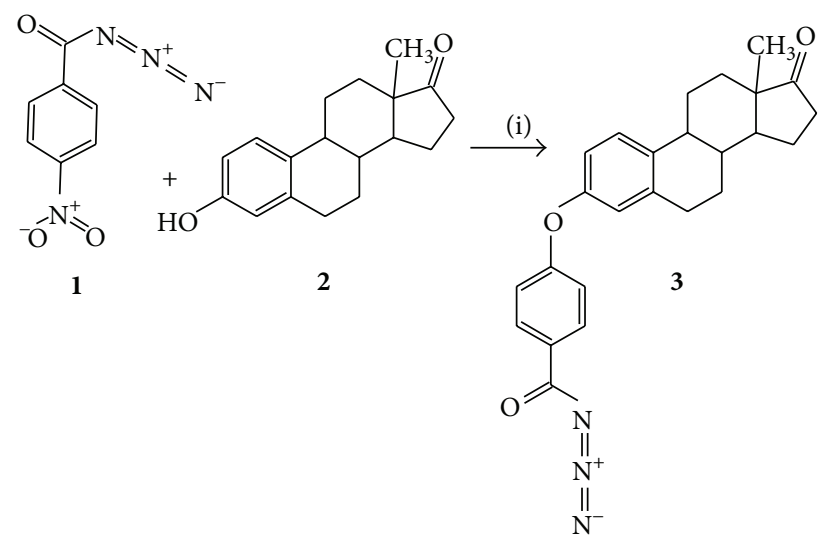

FIGURE 1: Synthesis of 4-(13-methyl-17-oxo-7,8,9,11,12,13,14,15,16,17decahydro-6-H-cyclopen ta[a]phenanthren-3-yloxy)-benzoyl azide (3). Reaction of $p$-nitrobenzoyl azide (1) with estrone (2) to form 3. (i) = potassium carbonate/dimethyl sulfoxide.

are available for synthesis of indole derivatives; nevertheless, expensive reagents and special conditions are required. Therefore, in this study, an indole-steroid derivative was synthetized using some strategies.

\section{Experimental}

The compounds evaluated in this study were purchased from Sigma-Aldrich Co., Ltd. The melting points for the different compounds were determined on an Electrothermal (900 model). Infrared spectra (IR) were recorded using $\mathrm{KBr}$ pellets on a Perkin Elmer Lambda 40 spectrometer. ${ }^{1} \mathrm{H}$ and ${ }^{13} \mathrm{C}$ NMR spectra were recorded on a Varian VXR-300/5 FT NMR spectrometer at 300 and $75.4 \mathrm{MHz}$ in $\mathrm{CDCl}_{3}$ using TMS as internal standard. EIMS spectra were obtained with a Finnigan Trace GC Polaris Q. spectrometer. Elementary analysis data were acquired from a Perkin Elmer Ser. II CHNS/0 2400 elemental analyzer. The parameter $\left[\mathrm{M}^{+}\right]$indicates ion molecular.

2.1. Synthesis of 4-(13-Methyl-17-oxo-7,8,9,11,12,13,14,15,16,17decahydro-6-H-cyclo-penta[a]phenanthren-3-yloxy)-benzoyl azide (3). A solution of 4-nitrobenzoyl azide (100 mg, $0.52 \mathrm{mmol}$ ), estrone $(140 \mathrm{mg}, 0.52 \mathrm{mmol}$ ), and potassium carbonate $(40 \mathrm{mg}, 0.30 \mathrm{mmol}$ ) in $10 \mathrm{~mL}$ of dimethyl sulfoxide was stirring for $72 \mathrm{~h}$ at room temperature (Figure 1). The reaction mixture was evaporated to a smaller volume. After the mixture was diluted with water and extracted with chloroform, the organic phase was evaporated to dryness under reduced pressure and the residue was purified by crystallization from methanol: water $(3: 1)$ yielding $66 \%$ of product, m.p. $268-270^{\circ} \mathrm{C}$; IR $\left(V_{\max }, \mathrm{cm}^{-1}\right): 1724,2112$, and $1250 ;{ }^{1} \mathrm{H}$ NMR $\left(300 \mathrm{MHz}, \mathrm{CDCl}_{3}\right) \delta_{\mathrm{H}}: 0.94(\mathrm{~s}, 3 \mathrm{H}), 1.18-1.50$ (m, 5H), $1.76-1.90(\mathrm{~m}, 2 \mathrm{H}), 2.00-2.20(\mathrm{~m}, 4 \mathrm{H}), 2.40-3.00$ $(\mathrm{m}, 4 \mathrm{H}), 6.60-6.70(\mathrm{~m}, 2 \mathrm{H}), 6.90(\mathrm{~m}, 2 \mathrm{H}, J=2.40 \mathrm{~Hz}), 7.10$ $(\mathrm{m}, 1 \mathrm{H}), 7.76(\mathrm{~m}, 2 \mathrm{H}) \mathrm{ppm} .{ }^{13} \mathrm{C} \mathrm{NMR}\left(75.4 \mathrm{MHz}, \mathrm{CDCl}_{3}\right)$ $\delta_{\mathrm{C}}: 13.16,21.66,25.70,26.34,29.22,30.90,35.56,37.55,44.70$, $48.00,48.60,114.20,114.44,115.30,124.60,125.00,129.36$,<smiles></smiles><smiles></smiles>

FigURE 2: Synthesis of 3- (tert-butyl- dimethyl- silanyloxy) - NH indolo $\left[2^{\prime} 3^{\prime}: 17,16\right]$ estra-1,3,5(10)-triene (5). The first stage involves protection of hydroxyl group from estrone (2) with tertbutyldimethylsilyl chloride (ii) to form the compound 4 (3-(tertbutyl-dimethyl-silanyloxy)-13-methyl-6,7,8,9,11,12,13,14,15,16-decahydro-cyclopenta[a]phenanthren-17-one). In the following stage, 4 was made reacting with phenylhydrazine hydrochloride to the synthesis of 5. (iii) = and acetic acid/methanol.

$132.46,139.48,154.76,163.56,170.32,219.76 \mathrm{ppm}$. EI-MS $m / z$ : $415.18\left(\mathrm{M}^{+} 12\right)$. Anal. Calcd. for $\mathrm{C}_{25} \mathrm{H}_{25} \mathrm{~N}_{3} \mathrm{O}_{3}$ : C, 72.27; $\mathrm{H}$, 6.06; N, 10.11; O, 11.55. Found: C, 72.26; H, 6.02.

2.2. Synthesis of 3-(Tert-butyl-dimethyl-silanyloxy)-13-methyl6,7,8,9,11,12,13,14,15,16-decahydro-cyclopenta[a]phenanthren17-one (4). A solution of estrone $(100 \mathrm{mg}, 0.37 \mathrm{mmol})$ and tert-Butyldimethylsilyl chloride $(200 \mu \mathrm{L}, 1.07 \mathrm{mmol})$ in $5 \mathrm{~mL}$ of methanol was stirring for $8 \mathrm{~h}$ at room temperature (Figure 2). The reaction mixture was evaporated to a smaller volume. After the mixture was diluted with water and extracted with chloroform, the organic phase was evaporated to dryness under reduced pressure and the residue was purified by crystallization from methanol: water $(4: 1)$ yielding $87 \%$ of product, m.p. $224-226^{\circ} \mathrm{C}$; IR $\left(V_{\max }, \mathrm{cm}^{-1}\right)$ : 1728 and $1148 ;{ }^{1} \mathrm{H}$ NMR $\left(300 \mathrm{MHz}, \mathrm{CDCl}_{3}\right) \delta_{\mathrm{H}}: 0.28(\mathrm{~s}, 6 \mathrm{H})$, $0.96(\mathrm{~s}, 3 \mathrm{H}), 1.04(\mathrm{~s}, 9 \mathrm{H}), 1.24-1.36(\mathrm{~m}, 4 \mathrm{H}), 1.50-1.90(\mathrm{~m}$, $3 \mathrm{H}), 2.10-2.22(\mathrm{~m}, 4 \mathrm{H}), 2.46-3.00(\mathrm{~m}, 4 \mathrm{H}), 6.70(\mathrm{~m}, 1 \mathrm{H}$, $J=1.00 \mathrm{~Hz}), 6.78-7.36(\mathrm{~m}, 2 \mathrm{H}) \mathrm{ppm} .{ }^{13} \mathrm{C}$ NMR $(75.4 \mathrm{MHz}$, $\left.\mathrm{CDCl}_{3}\right) \delta_{\mathrm{C}}:-4.40,13.45,18.06,21.70,25.66,25.80,26.44$, $29.50,31.20,35.18,37.00,43.40,48.12,49.14,117.02,119.90$, $125.88,132.08,137.50,153.30,219.64 \mathrm{ppm}$. EI-MS m/z: 384.22 $\left(\mathrm{M}^{+} 10\right)$. Anal. Calcd. for $\mathrm{C}_{24} \mathrm{H}_{36} \mathrm{O}_{2}$ Si: C, 74.94; H, 9.43; O, 8.32; Si, 7.30. Found: C, 74.92; H, 9.42.

2.3. Synthesis of 3-(Tert-butyl-dimethyl-silanyloxy)-NH-indolo [2' $\left.3^{\prime}: 17,16\right]$ estra-1,3,5(10)-triene (5). A solution of $4(100 \mathrm{mg}$, 


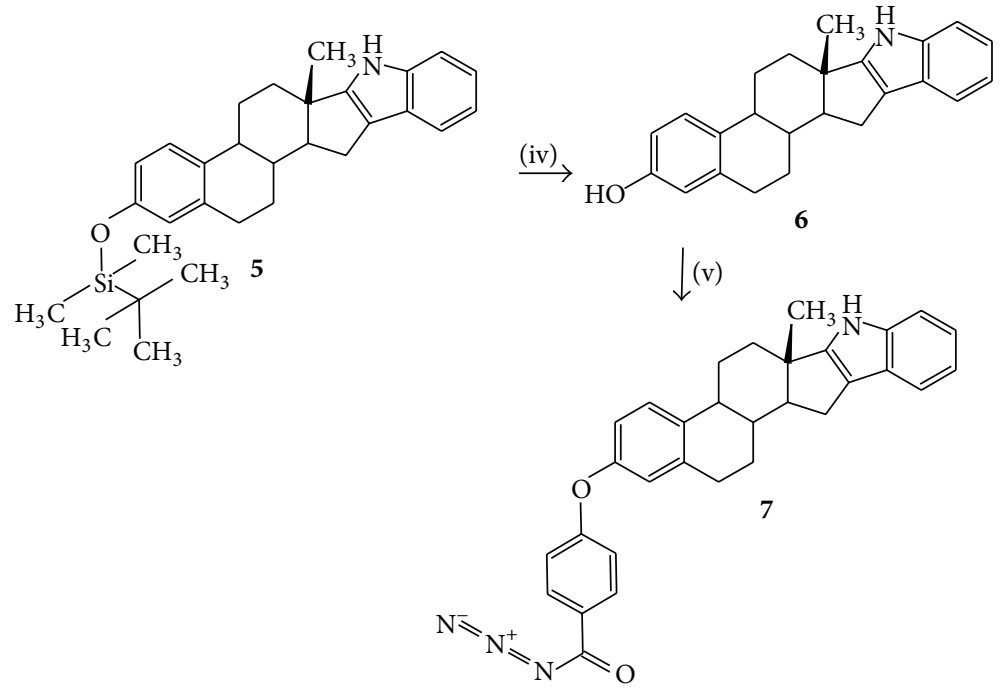

FIGURE 3: Synthesis of 3-(4-azidocarbonyl-phenoxy)-NH-indolo[ $\left[2^{\prime}, 3^{\prime}: 17,16\right]$ estra-1,3,5(10)-triene (7). The first stage was achieved by the reaction of 5 with hydrofluoric acid (iv) to form compound 6 ( $\mathrm{NH}$-indolo $\left[2^{\prime}, 3^{\prime}: 17,16\right]$ estra-1,3,5(10)trien-3-ol). In addition, 6 was made reacting with $p$-nitrobenzoyl azide for synthesis of 7 . (v) $=$ dimethyl sulfoxide.

$0.25 \mathrm{mmol})$, phenylhydrazine hydrochloride $(70 \mathrm{mg}$, $0.48 \mathrm{mmol})$, and acetic acid $(1 \mathrm{~mL})$ in $10 \mathrm{~mL}$ of methanol was stirring for $72 \mathrm{~h}$ at room temperature. The reaction mixture was evaporated to a smaller volume. After the mixture was diluted with water and extracted with chloroform, the organic phase was evaporated to dryness under reduced pressure and the residue was purified by crystallization from methanol: water:hexano $(3: 1: 2)$ yielding $44 \%$ of product, m.p. $200-202^{\circ} \mathrm{C}$; IR $\left(V_{\max }, \mathrm{cm}^{-1}\right): 3520$ and 1150 ; ${ }^{1} \mathrm{H}$ NMR $\left(300 \mathrm{MHz}, \mathrm{CDCl}_{3}\right) \delta_{H}: 0.26(\mathrm{~s}, 6 \mathrm{H}), 1.06(\mathrm{~s}, 9 \mathrm{H})$, $1.28-1.50(\mathrm{~m}, 2 \mathrm{H}), 1.60(\mathrm{~s}, 3 \mathrm{H}), 1.68-1.98$ (m, 3H), 2.00-2.86 $(\mathrm{m}, 7 \mathrm{H}), 3.10(\mathrm{~m}, 1 \mathrm{H}), 6.70-6.82(\mathrm{~m}, 2 \mathrm{H}), 7.10(\mathrm{~m}, 1 \mathrm{H}$, $J=7.60 \mathrm{~Hz}), 7.20-7.25(\mathrm{~m}, 2 \mathrm{H}), 7.30(\mathrm{~m}, 1 \mathrm{H}), 7.40(\mathrm{~m}, 1 \mathrm{H})$ and $8.30($ broad $1 \mathrm{H})$ ppm. ${ }^{13} \mathrm{C} \mathrm{NMR}\left(75.4 \mathrm{MHz} \mathrm{CDCl}_{3}\right) \delta_{\mathrm{C}}$ : $-4.40,18.08,19.20,25.60,26.70,27.80,29.44,31.10,35.22$, $35.30,36.70,44.90,48.90,110.80,114.66,117.10,118.06,119.00$, $119.92,120.90,125.48,126.10,133.88,134.85,137.66,153.30$, $153.34 \mathrm{ppm}$. EI-MS m/z: $457.26\left(\mathrm{M}^{+} 12\right)$. Anal. Calcd. for $\mathrm{C}_{30} \mathrm{H}_{39}$ NOSi: C, 78.72; H, 8.59; N, 3.06; O, 3.50; Si, 6.14. Found: C, 78.70; H, 8.56.

2.4. Synthesis of $\mathrm{NH}$-indolo $\left[2^{\prime}, 3^{\prime}: 17,16\right]$ estra-1,3,5(10)trien-3-ol (6). A solution of $5(100 \mathrm{mg}, 0.21 \mathrm{mmol})$ and hydrofluoric acid $(2 \mathrm{~mL})$ in $8 \mathrm{~mL}$ of methanol was stirring for $72 \mathrm{~h}$ at room temperature. The reaction mixture was evaporated to a smaller volume. After the mixture was diluted with water and extracted with chloroform, the organic phase was evaporated to dryness under reduced pressure and the residue was purified by crystallization from methanol : water $(4: 1)$ yielding $85 \%$ of product, m.p. $318-320^{\circ} \mathrm{C}$; IR $\left(V_{\max }, \mathrm{cm}^{-1}\right): 3520$ and $3408 ;{ }^{1} \mathrm{H}$ NMR $\left(300 \mathrm{MHz}, \mathrm{CDCl}_{3}\right) \delta_{\mathrm{H}}: 1.28-1.50(\mathrm{~m}, 2 \mathrm{H}), 1.54$ (s, 3H), 1.62-2.10 (m, 6H), 2.62-2.80 (m, 4H), $3.10(\mathrm{~m}, 1 \mathrm{H})$, 6.54-6.62 (m, 2H), 7.00 (broad, $2 \mathrm{H}), 7.10(\mathrm{~m}, 1 \mathrm{H}, J=7.60 \mathrm{~Hz})$, $7.20(\mathrm{~m}, 1 \mathrm{H})$ and 7.24-7.48 (m, 3H) ppm. ${ }^{13} \mathrm{C} \mathrm{NMR}(75.4 \mathrm{MHz}$, $\left.\mathrm{CDCl}_{3}\right) \delta_{\mathrm{C}}: 19.18,26.88,27.50,29.80,31.00,35.22,35.40,36.70$,
44.59, 48.86, 110.80, 113.20, 114.54, 115.44,118.16, 119.00, 120.90, $125.56,126.40,134.26,134.80,137.42,153.30,155.00$ ppm. EIMS m/z: $343.18\left(\mathrm{M}^{+}\right.$8). Anal. Calcd. for $\mathrm{C}_{24} \mathrm{H}_{25} \mathrm{NO}$ : C, 83.93; H, 7.34; N, 4.08; O, 4.66. Found: C, 83.90; H, 7.32.

2.5. Synthesis of 3-(4-Azidocarbonyl-phenoxy)-NH-indolo $\left[2^{\prime}\right.$, $\left.3^{\prime}: 17,16\right]$ estra-1,3,5(10)-triene (7). A solution of 6 (100 mg, $0.29 \mathrm{mmol}), \mathrm{p}$-nitrobenzoyl azide $(60 \mathrm{mg}, 0.31 \mathrm{mmol})$, and potassium carbonate $(40 \mathrm{mg}, 0.30 \mathrm{mmol}$ ) in $10 \mathrm{~mL}$ of dimethyl sulfoxide was stirring for $72 \mathrm{~h}$ at room temperature (Figure 3). The reaction mixture was evaporated to a smaller volume. After the mixture was diluted with water and extracted with chloroform, the organic phase was evaporated to dryness under reduced pressure and the residue was purified by crystallization from methanol : water : hexano $(1: 3: 1)$ yielding $80 \%$ of product, m.p. $258-260^{\circ} \mathrm{C}$; IR $\left(V_{\max }, \mathrm{cm}^{-1}\right)$ : 3522, 2123, and $1152 ;{ }^{1} \mathrm{H}$ NMR $\left(300 \mathrm{MHz}, \mathrm{CDCl}_{3}\right) \delta_{\mathrm{H}}: 1.30-$ $1.50(\mathrm{~m}, 2 \mathrm{H}), 1.60(\mathrm{~s}, 3 \mathrm{H}), 1.68-2.08(\mathrm{~m}, 6 \mathrm{H}), 2.66-2.80(\mathrm{~m}$, $4 \mathrm{H}), 3.10(\mathrm{~m}, 1 \mathrm{H}), 6.62-6.70(\mathrm{~m}, 2 \mathrm{H}), 6.90(\mathrm{~m}, 2 \mathrm{H}), 7.00(\mathrm{~m}$, $1 \mathrm{H}), 7.12-7.40(\mathrm{~m}, 4 \mathrm{H}), 7.78(\mathrm{~m}, 2 \mathrm{H}, J=8.37 \mathrm{~Hz})$ and 8.30 (broad $1 \mathrm{H})$ ppm. ${ }^{13} \mathrm{C}$ NMR $\left(75.4 \mathrm{MHz}, \mathrm{CDCl}_{3}\right) \delta_{\mathrm{C}}: 19.20$, 26.70, 27.50, 29.84, 31.08, 35.22, 35.42, 36.70, 44.44, 48.94, $110.80,114.18,114.50,114.70,115.22,118.22,119.00,120.90$, $123.45,124.70,125.60,132.50,134.10,134.78,139.72,153.30$, 154.78, 163.80, 171.52 ppm. EI-MS $m / z: 488.20\left(\mathrm{M}^{+} 8\right)$. Anal. Calcd. for $\mathrm{C}_{31} \mathrm{H}_{28} \mathrm{~N}_{4} \mathrm{O}_{2}$ : C, 76.21; H, 5.78; N, 11.47; O, 6.55. Found: C, 76.20; H, 5.76.

2.6. Synthesis of N-(3-Butyl-1-cyclohexyl-4-cyclohexyliminoazetidin-2-ylidene)-4-(13-methyl-17-oxo-7,8,9,11,12,13,14,15,16, 17-decahydro-6H-cyclopenta [a]phenanthren-3-yloxy)-benzamide (11). A solution of 3 (300 mg, $0.72 \mathrm{mmol})$, 1-hexyne ( $90 \mu \mathrm{L}, 0.78 \mathrm{mmol}), N, N^{\prime}$-Dicyclohexylcarbodiimide (150 mg, $0.72 \mathrm{mmol}$ ), and cupric chloride anhydrous (100 mg, $0.72 \mathrm{mmol})$ in $8 \mathrm{~mL}$ of methanol/dimethyl sulfoxide $(2: 6)$ 


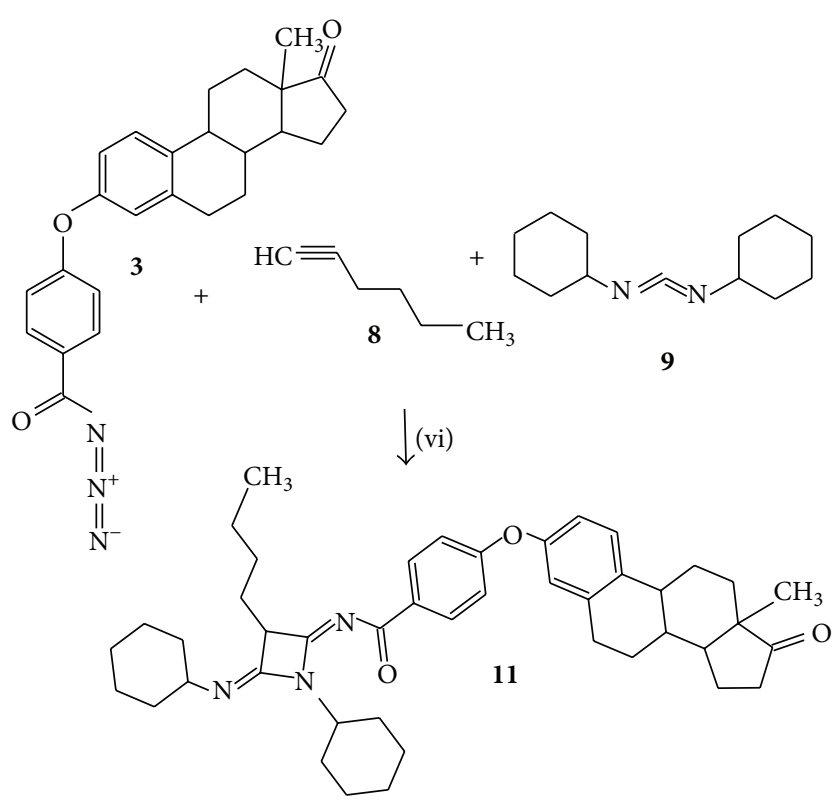

FIGURE 4: Synthesis of $N$-(3-butyl-1-cyclohexyl-4-cyclohexyliminoazetidin-2-ylidene)-4-(13-methyl-17-oxo-7,8,9,11,12,13,14,15,16,17-decahydro-6H-cyclopenta[a] phenanthren-3-yloxy)-benzamide (11). Reaction of 3 with 1-hexyne (8) and $N, N^{\prime}$-Dicyclohexylcarbodiimide (9) to form 11. (vi) = methanol/dimethyl sulfoxide.

was stirring for $72 \mathrm{~h}$ at room temperature (Figure 4 ). The reaction mixture was evaporated to a smaller volume. After the mixture was diluted with water and extracted with chloroform, the organic phase was evaporated to dryness under reduced pressure and the residue was purified by crystallization from methanol: water $(3: 1)$ yielding $66 \%$ of product, m.p. $262-264^{\circ} \mathrm{C}$; IR $\left(V_{\max }, \mathrm{cm}^{-1}\right): 1720,1650$, and $1148 ;{ }^{1} \mathrm{H}$ NMR $\left(300 \mathrm{MHz}, \mathrm{CDCl}_{3}\right) \delta_{\mathrm{H}}: 0.86(\mathrm{~s}, 3 \mathrm{H})$, $0.96(\mathrm{~s}, 3 \mathrm{H}), 1.02-1.16(\mathrm{~m}, 6 \mathrm{H}), 1.20(\mathrm{~m}, 1 \mathrm{H}), 1.22(\mathrm{~m}, 1 \mathrm{H})$, $1.24-1.26(\mathrm{~m}, 2 \mathrm{H}), 1.29(\mathrm{~m}, 1 \mathrm{H}), 1.34(\mathrm{~m}, 1 \mathrm{H}), 1.36-1.44(\mathrm{~m}$, $6 \mathrm{H}), 1.48(\mathrm{~m}, 2 \mathrm{H}), 1.50-1.53(\mathrm{~m}, 3 \mathrm{H}), 1.54(\mathrm{~m}, 1 \mathrm{H}), 1.60(\mathrm{t}$, $2 \mathrm{H}, J=1.09 \mathrm{~Hz}), 1.62-1.66(\mathrm{~m}, 3 \mathrm{H}), 1.76(\mathrm{~m}, 1 \mathrm{H}), 1.78(\mathrm{~m}$, $1 \mathrm{H}), 1.90(\mathrm{~m}, 1 \mathrm{H}), 1.92-3.00(\mathrm{~m}, 9 \mathrm{H}), 3.10-3.20(\mathrm{~m}, 2 \mathrm{H}), 4.70$ $(\mathrm{m}, 1 \mathrm{H}), 6.60-672(\mathrm{~m}, 2 \mathrm{H}), 6.90(\mathrm{~m}, 2 \mathrm{H}), 7.10(\mathrm{~m}, 1 \mathrm{H})$ and $8.36(\mathrm{~m}, 2 \mathrm{H}) \mathrm{ppm} .{ }^{13} \mathrm{C} \mathrm{NMR}\left(75.4 \mathrm{MHz}, \mathrm{CDCl}_{3}\right) \delta_{\mathrm{C}}: 13.58$, $14.12,21.66,23.00,23.10,24.36,25.40,25.70,26.06,26.34$, $26.36,29.18,29.30,29.70,30.78,32.27,35.60,37.55,38.70$, $44.65,48.00,48.65,57.90,59.74,114.24,114.55,116.68,124.60$, $131.00,132.48,132.65,134.38,139.50,154.80,163.67,164.16$, $175.88,219.76$ ppm. EI-MS m/z: $675.42\left(\mathrm{M}^{+} 12\right)$. Anal. Calcd. for $\mathrm{C}_{44} \mathrm{H}_{57} \mathrm{~N}_{3} \mathrm{O}_{3}$ : C, 78.18; H, 8.50; N, 6.22; O, 7.10. Found: C, 78.16; $\mathrm{H}, 8.47$.

\subsection{Synthesis of 3-[4-(2-Butyl-3-cyclohexylimino-4-piperidin- 1-yl-cyclobutylidencarbamoyl)]-phenoxy-NH-indolo $\left[2^{\prime}, 3^{\prime}\right.$ : 17,16]estra-1,3,5(10)triene (10)}

2.7.1. Method A. A solution of 7 (300 mg, $0.61 \mathrm{mmol}), 1-$ hexyne $(90 \mu \mathrm{L}, 0.78 \mathrm{mmol}), N, N^{\prime}$-dicyclohexylcarbodiimide (150 mg, $0.72 \mathrm{mmol}$ ), and cupric chloride anhydrous (100 mg, $0.72 \mathrm{mmol})$ in $8 \mathrm{~mL}$ of methanol/dimethyl sulfoxide $(2: 6)$ was stirring for $72 \mathrm{~h}$ at room temperature. The reaction mixture was evaporated to a smaller volume. After the mixture was diluted with water and extracted with chloroform, the organic phase was evaporated to dryness under reduced pressure and the residue was purified by crystallization from methanol: water $(3: 1)$ yielding $66 \%$ of product, m.p. 238$240^{\circ} \mathrm{C}$; IR $\left(V_{\max }, \mathrm{cm}^{-1}\right): 3520,3320,1166$, and $1152 ;{ }^{1} \mathrm{H}$ NMR $\left(300 \mathrm{MHz}_{\mathrm{CDCl}}\right) \delta_{\mathrm{H}}: 0.86(\mathrm{~s}, 3 \mathrm{H}), 1.08-1.28(\mathrm{~m}, 8 \mathrm{H}), 1.30$ $(\mathrm{m}, 1 \mathrm{H}), 1.36-1.44(\mathrm{~m}, 6 \mathrm{H}), 1.48(\mathrm{~m}, 2 \mathrm{H}), 1.50-1.54(\mathrm{~m}, 3 \mathrm{H})$, $1.58(\mathrm{t}, 2 \mathrm{H}, J=1.10 \mathrm{~Hz}), 1.60(\mathrm{~s}, 3 \mathrm{H}), 1.60(\mathrm{~m}, 1 \mathrm{H}), 1.62(\mathrm{~m}$, $1 \mathrm{H}), 1.63(\mathrm{~m}, 1 \mathrm{H}), 1.66(\mathrm{~m}, 2 \mathrm{H}), 1.76(\mathrm{~m}, 1 \mathrm{H}), 1.84-1.86(\mathrm{~m}$, $2 \mathrm{H}), 1.92(\mathrm{~m}, 1 \mathrm{H}), 1.96-3.10(\mathrm{~m}, 8 \mathrm{H}), 3.18-3.22(\mathrm{~m}, 2 \mathrm{H}), 4.70$ (m, 1H), 6.60-7.00 (m, 5H), 7.10-7.40 (m, 4H), 8.34-9.20 (m, $3 \mathrm{H}) \mathrm{ppm} .{ }^{13} \mathrm{C} \mathrm{NMR}\left(75.4 \mathrm{MHz}, \mathrm{CDCl}_{3}\right) \delta_{\mathrm{C}}: 14.18,23.00,23.10$, $24.32,24.38,25.44,26.00,26.34,26.70,27.44,29.18,29.65$, $29.70,31.10,32.27,35.58,36.44,38.70,38.92,44.50,48.67$, 57.90, 59.74, 111.64, 114.24, 114.55, 116.75, 117.48, 118.56, 119.20, $119.64,124.66,125.10,130.98,132.60,134.28,134.34,139.70$, $140.66,149.24,154.80,163.45,164.10,175.88 \mathrm{ppm}$. EI-MS $m / z$ : 748.46 ( $\left.\mathrm{M}^{+} 10\right)$. Anal. Calcd. for $\mathrm{C}_{50} \mathrm{H}_{60} \mathrm{~N}_{4} \mathrm{O}_{2}: \mathrm{C}, 80.17 ; \mathrm{H}$, 8.07; N, 7.48; O, 4.27. Found: C, 80.14; H, 8.0.6.

2.7.2. Method B. A solution of 11 (100 mg, $0.25 \mathrm{mmol})$, phenylhydrazine hydrochloride $(70 \mathrm{mg}, 0.48 \mathrm{mmol})$, and acetic acid $(1 \mathrm{~mL})$ in $10 \mathrm{~mL}$ of methanol was stirring for $72 \mathrm{~h}$ at room temperature. The reaction mixture was evaporated to a smaller volume. After the mixture was diluted with water and extracted with chloroform, the organic phase was evaporated to dryness under reduced pressure and the residue was purified by crystallization from methanol: water (4:1) yielding $78 \%$ of product. The signals IR, ${ }^{1} \mathrm{H}$ NMR, and ${ }^{13} \mathrm{C}$ NMR were confirmed by spectroscopic analyses. Similar signals were obtained as in the first method mentioned above.

\section{Results and Discussion}

In this study, an indole-steroid derivative was developed using some strategies; the first step was achieved by the synthesis of 4-(13-methyl-17-oxo-7,8,9,11,12,13,14,15,16,17decahydro-6-H-cyclopenta[a]phenanthren-3-yloxy)-benzoyl azide (3) via displacement of nitro group from 4-nitrobenzoyl azide. It is important to mention that there are several methods for displacement of nitro groups, for example, the synthesis of bis(2-bromo-4-methoxyphenyl)methanone by the reaction of $2,2^{\prime}$ dibromo- $4,4^{\prime}$ dinitrobenzophenone with methoxide using a dipolar aprotic solvent. In general, dipolar solvents are used to attain high yield of ether groups $[14,15]$. In this study, compound 3 was synthesized by the reaction of 4-nitrobenzoyl azide with estrone in presence of dimethyl sulfoxide at mild conditions. The ${ }^{1} \mathrm{H}$ NMR spectrum of 3 shows signals at $0.94 \mathrm{ppm}$ for methyl group bound to steroid nucleus; at 1.18-6.70 and $7.10 \mathrm{ppm}$ for steroid moiety; and at 6.90 and $7.76 \mathrm{ppm}$ for protons of benzoyl azide group. The ${ }^{13} \mathrm{C}$ NMR spectrum of 3 contains peaks at $13.16 \mathrm{ppm}$ for methyl group bound to steroid nucleus; at 21.66-114.44, 124.60, and 132.46154.76 ppm for steroid moiety; at 115.30, 125.00-129.36, and $163.56 \mathrm{ppm}$ for phenyl bound to amide group; at $170.32 \mathrm{ppm}$ 
for amide group; and at $219.76 \mathrm{ppm}$ for ketone group. Finally, the presence of compound $\mathbf{3}$ was further confirmed from mass spectrum which showed a molecular ion at $m / z$ 415.18.

The second reaction stage was accomplished by protecting the hydroxyl group of the estrone in order to avoid possible reaction of hydroxyl group with any substance involved in the following reaction. It is important to mention that several organosilyl groups have been employed for protection of hydroxyl groups such as tertbutyldimethylsilyl and tert-butyldiphenylsilyl [16]. In this study, the estrone was made reacting with tert-butyldimethylsilyl chloride to form 3-(tert-Butyl-dimethyl-silanyloxy)-13-methyl-6,7,8,9,11,12,13,14,15,16-decahydro-cyclopenta[a]phenanthren-17-one (4). The ${ }^{1} \mathrm{H}$ NMR spectrum of 4 shows signals at 0.28 and $1.04 \mathrm{ppm}$ for methyl groups involved in the tert-butyldimethylsilane fragment; at $0.96 \mathrm{ppm}$ for methyl group bound to steroid nucleus; and at 1.24-7.36 ppm for steroid moiety. The ${ }^{13} \mathrm{C}$ NMR spectrum of 4 contains peaks at -4.40 and $25.66 \mathrm{ppm}$ for methyl groups involved in the tert-butyldimethylsilane fragment; at $13.45 \mathrm{ppm}$ for methyl group bound to steroid nucleus; at $18.06 \mathrm{ppm}$ for carbon bound to methyl groups involved in the tertbutyldimethylsilane fragment; at $21.70-153.30 \mathrm{ppm}$ for steroid moiety; and at $219.64 \mathrm{ppm}$ for ketone group. Finally, the presence of compound $\mathbf{4}$ was further confirmed from mass spectrum which showed a molecular ion at $m / z 384.22$.

The third stage was achieved by the synthesis of an indole-steroid derivative (5); it is important to mention that there are several procedures which are available for synthesis of indole derivatives; nevertheless, expensive reagents and special conditions are required [5-12]. Therefore, in this study, the Fischer indole method was used to form $\mathbf{5}$ by the reaction of 4 with phenylhydrazine in mild medium. The ${ }^{1} \mathrm{H}$ NMR spectrum of 5 shows signals at 0.26 and $1.06 \mathrm{ppm}$ for methyl groups involved in the tert-butyldimethylsilane fragment; at $1.60 \mathrm{ppm}$ for methyl group bound to steroid nucleus; at $1.28-1.50,1.68-6.82$, and $7.30 \mathrm{ppm}$ for steroid moiety; at 7.10-7.40 ppm for protons involved in indole group; and at $8.30 \mathrm{ppm}$ for amino group. The ${ }^{13} \mathrm{C}$ NMR spectrum of 5 contains peaks at -4.40 and $25.60 \mathrm{ppm}$ for methyl groups involved in the tert-butyldimethylsilane fragment; at $18.08 \mathrm{ppm}$ for carbon bound to methyl groups involved in the tert-butyldimethylsilane fragment; at $19.20 \mathrm{ppm}$ for methyl group bound to steroid nucleus; at 26.70-48.90, $114.54-117.10,119.92,126.10-133.88$, and $137.66-153.34 \mathrm{ppm}$ for steroid moiety; and at 110.80, 118.06-119.00, 120.90-125.48, and $134.85 \mathrm{ppm}$ for indole group. Finally, the presence of compound $\mathbf{5}$ was further confirmed from mass spectrum which showed a molecular ion at $m / z$ 457.28.

The following stage was achieved with the synthesis of NH-indolo[ $\left.2^{\prime}, 3^{\prime}: 17,16\right]$ estra-1,3,5(10)trien-3-ol (6) by the reaction of $\mathbf{5}$ with hydrofluoric acid which is an excellent reagent for the removal of the t-butyldimethylsilyl protecting group [17]. The ${ }^{1} \mathrm{H}$ NMR spectrum of $\mathbf{6}$ shows signals at 1.28$1.50,1.62-6.62$, and $7.20 \mathrm{ppm}$ for steroid moiety; at $1.54 \mathrm{ppm}$ for methyl group bound to steroid nucleus; at $7.00 \mathrm{ppm}$ for the protons of both amino and hydroxyl groups; and at 7.10 and 7.24-7.48 ppm for indole group. The ${ }^{13} \mathrm{C}$ NMR spectrum of 6 contains peaks at $19.18 \mathrm{ppm}$ for methyl group; at 26.88$48.66,113.20-115.44,126.40-134.26$, and $137.42-155.00 \mathrm{ppm}$ for steroid moiety; at 110.80, 118.16-125.56, and $134.80 \mathrm{ppm}$ for indole group. Finally, the presence of compound $\mathbf{6}$ was further confirmed from mass spectrum which showed a molecular ion at $m / z 343.18$.

On the other hand, the fifth stage was achieved by preparation of $\mathbf{7}$ by reaction of $\mathbf{6}$ with $p$-nitrobenzoyl azide. The ${ }^{1} \mathrm{H}$ NMR spectrum of 7 shows signals at $1.60 \mathrm{ppm}$ for methyl group bound to steroid nucleus; at 1.30-1.50, 1.686.70 , and $7.00 \mathrm{ppm}$ for steroid moiety; at 6.90 and $7.78 \mathrm{ppm}$ for benzoyl azide group; at 7.12-7.40 ppm for indole group; and at $8.30 \mathrm{ppm}$ for amino group. The ${ }^{13} \mathrm{C}$ NMR spectrum of 7 contains peaks at $19.20 \mathrm{ppm}$ for methyl group bound to steroid nucleus; at 26.70-48.94, 114.18-114.70, 124.70, 134.10, and $139.72-154.78 \mathrm{ppm}$ for steroid moiety; at $110.80,118.22-$ 120.90 , and $134.78 \mathrm{ppm}$ for indole group; at 115.22, 123.45, $125.60-132.50$, and $163.80 \mathrm{ppm}$ for benzoyl azide group; and at $171.52 \mathrm{ppm}$ for amide group. Finally, the presence of compound 7 was further confirmed from mass spectrum which showed a molecular ion at $m / z 488.20$.

In the following stage, the compound $N$-(3-butyl-1-cyclohexyl-4-cyclohexylimino-azetidin-2-ylidene)-4-(13-methyl17 - oxo-7,8,9,11,12,13,14,15,16,17-decahydro-6H-cyclopenta[a] phenanthren-3-yloxy)-benzamide (11) was prepared with the three-component system (compound 3, 1-hexyne, and $N, N^{\prime}$ dicyclohexylcarbodiimide) using cupric chloride as catalyst. It is important to mention that the reaction mechanism involved may be through a $[2+2]$ cycloaddition such as happening with the other type of compounds [18]. The ${ }^{1} \mathrm{H}$ NMR spectrum of $\mathbf{1 1}$ shows signals at $0.86 \mathrm{ppm}$ for methyl group involved in the arm bound to azetidine ring; at $0.96 \mathrm{ppm}$ for methyl group bound to steroid nucleus; at $1.02-1.16,1.22,1.29,1.36-1.44,1.50-1.53,1.62-1.66$, and $3.10-3.20 \mathrm{ppm}$ for both cyclohexane rings; at 1.20, 1.24-1.26, $1.34,1.54,1.78,1.92-3.00,6.60-6.72$, and $7.10 \mathrm{ppm}$ for steroid moiety; at $1.48,1.60,1.76$, and $1.90 \mathrm{ppm}$ for methylene groups involved in the arm bound to azetidine ring; at $4.70 \mathrm{ppm}$ for proton of azetidine ring; and at 6.90 and $8.36 \mathrm{ppm}$ for phenyl group bound to both ether and amide groups. The ${ }^{13} \mathrm{C}$ NMR spectrum of $\mathbf{1 1}$ contains peaks at $13.58 \mathrm{ppm}$ for methyl group; at $14.12 \mathrm{ppm}$ for methyl group involved in the arm which is bound to azetidine ring; at 21.66, 25.70, 26.36, 29.30 , 30.78, 35.60-37.55, 44.65-48.65, 114.24-114.55, 124.60, 132.48 , and $139.50-154.80 \mathrm{ppm}$ for steroid moiety; at 23.00 , $24.36-25.40,26.06-26.34,32.27$, and $57.90-59.74 \mathrm{ppm}$ for both cyclohexane rings; at 23.10, 29.18, and $29.70 \mathrm{ppm}$ for methylene groups involved in the arm bound to azetidine ring; at $38.70 \mathrm{ppm}$ for carbon involved in the azetidine ring; at $116.68,131.00$, and $132.65 \mathrm{ppm}$ for phenyl group bound to both ether and amide groups; at $163.67 \mathrm{ppm}$ for ether group; at $164.16,134.38 \mathrm{ppm}$ for both imino groups; at $175.88 \mathrm{ppm}$ for amide group; and at $219.76 \mathrm{ppm}$ for ketone group. Finally, the presence of compound $\mathbf{1 1}$ was further confirmed from mass spectrum which showed a molecular ion at $m / z 675.42$. 


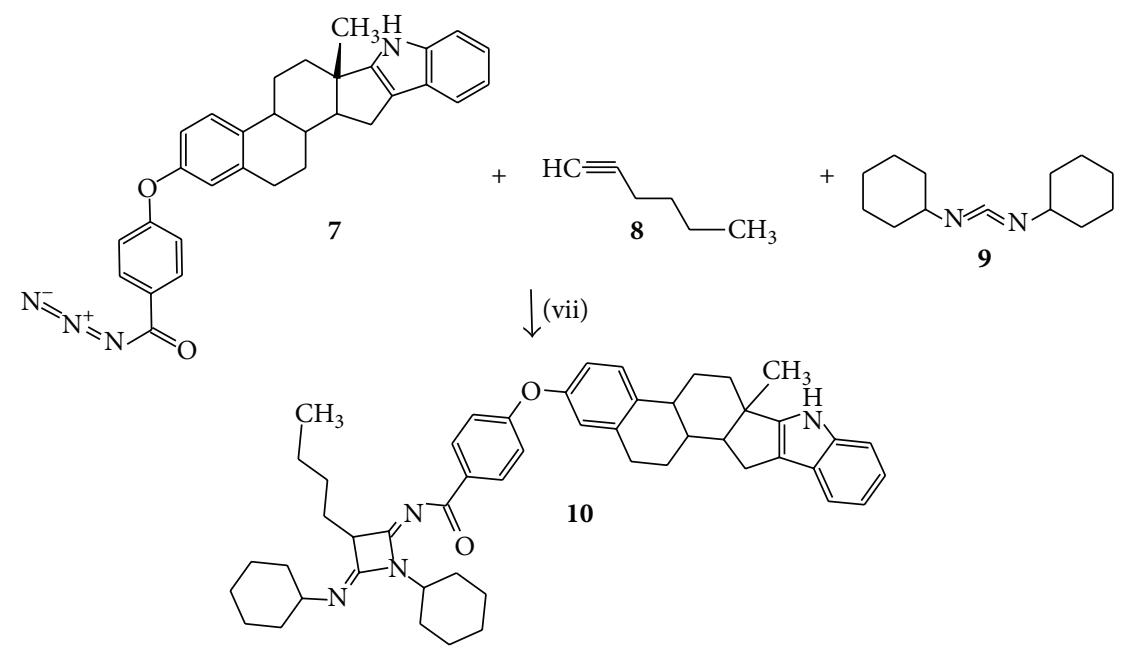

FIGURE 5: Synthesis of 3-[4-(2-butyl-3-cyclohexylimino-4-piperidin-1-yl-cyclobutylidencarbamoyl)]-phenoxy-NH-indolo[2' $\left.3^{\prime}: 17,16\right]$ estra1,3,5(10)triene (10). Reaction of 7 with 1-hexyne (8) and $N, N^{\prime}$-Dicyclohexylcarbodiimide (9) to form 10. (vii) = cupric chloride/rt.

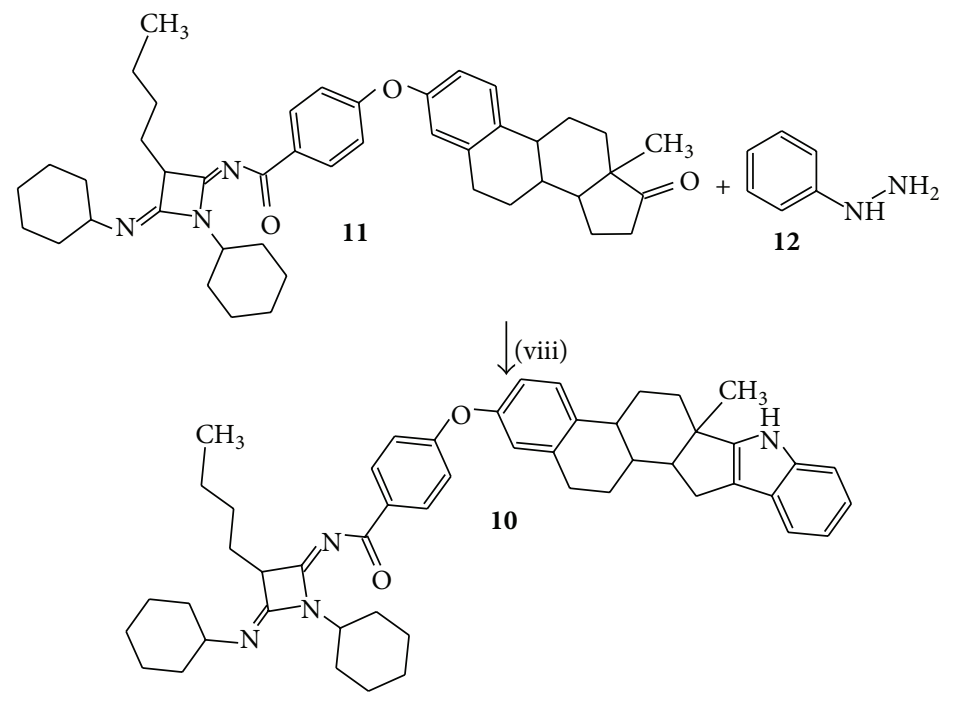

FIGURE 6: Synthesis of 3-[4-(2-butyl-3-cyclohexylimino-4-piperidin-1-yl-cyclobutylidencarbamoyl)]-phenoxy-NH-indolo[ $\left[2^{\prime}, 3^{\prime}: 17,16\right]$ estra1,3,5(10)triene (10). Reaction of $\mathbf{1 1}$ with phenylhydrazine hydrochloride (12) to form the compound $\mathbf{1 0}$. (viii) = acetic acid $/ \mathrm{methanol}$.

In addition, the last stage was achieved with the synthesis of 3-[4-(2-butyl-3-cyclohexylimino-4-piperidin-1-ylcyclobutylidencarbamoyl)-phenoxy]-indolo $\left[2^{\prime}, 3^{\prime}: 17,16\right]$ estra1,3,5(10)triene (10) with the three-component system (compound 7, 1-hexyne and $N, N^{\prime}$-Dicyclohexylcarbodiimide) using cupric chloride as catalyst (Method A) (Figure 5). The ${ }^{1} \mathrm{H}$ NMR spectrum of 10 shows signals at $0.86 \mathrm{ppm}$ for methyl involved in the arm bound to azetidine ring; at $1.08-1.28,1.36-1.44,1.50-1.54,1.62,1.66$, and $3.18-3.22 \mathrm{ppm}$ for both cyclohexane rings; at 1.30, 1.60, 1.63 1.84-1.86, $1.96-3.10$, and $6.60-7.00 \mathrm{ppm}$ for steroid moiety; at 1.48 , $1.58,1.76$, and $1.92 \mathrm{ppm}$ or methylene groups involved in the arm bound to azetidine group; at $1.60 \mathrm{ppm}$ for methyl group bound to steroid nucleus; at $4.70 \mathrm{ppm}$ for azetidine ring; at 7.10-7.40 ppm for indole group; and at 8.34-9.20 ppm for phenyl group bound to both ether and amide groups. The ${ }^{13} \mathrm{C}$ NMR spectrum of $\mathbf{1 0}$ contains peaks at $14.18 \mathrm{ppm}$ for methyl involved in the arm bound to azetidine ring; at $23.00,24.38-26.34,32.27$, and $57.90-59.74 \mathrm{ppm}$ for both cyclohexane rings; at 23.10 and $29.18-29.65$ for methylene involved in the arm bound to azetidine ring; at $24.32 \mathrm{ppm}$ for methyl group bound steroid nucleus; at 26.70-27.44, 29.70-31.10, 35.58-36.44, 38.92-48.67, 114.24-114.55, 117.48, $124.66-125.10,134.34-139.70$, and $149.24 \mathrm{ppm}$ for steroid moiety; at 38.70, 134.28, and $164.10 \mathrm{ppm}$ for azetidine ring; at $111.64,118.56-119.64$, and $140.66 \mathrm{ppm}$ for indole group; at 116.75 and $130.98-132.60 \mathrm{ppm}$ for phenyl group; at $154.80-$ $163.45 \mathrm{ppm}$ for carbons of ether; and at $175.88 \mathrm{ppm}$ for amide group. Finally, the presence of compound $\mathbf{1 0}$ was further confirmed from mass spectrum which showed a molecular 
ion at $m / z 748.46$ (Figure 6). Also 10 was synthesized using Fisher reaction by the reaction of $\mathbf{1 1}$ with phenylhydrazine in acid medium (Method B). ${ }^{1} \mathrm{H}$ NMR and ${ }^{13} \mathrm{C}$ NMR data were similar with two methods. However, it is important to mention that, with method $\mathrm{B}$, the yielding is higher in comparison with that of method A.

\section{Conclusions}

In conclusion, a facile procedure for the formation of an indole-estrogen derivative was developed in this study.

\section{Conflict of Interests}

The authors declare that they do not have any financial relations with any of the commercial entities mentioned in the paper that could lead to a conflict of interests.

\section{References}

[1] M. C. Rodríguez-Argüelles, E. C. López-Silva, J. Sanmartín, P. Pelagatti, and F. Zani, "Copper complexes of imidazole2-, pyrrole-2- and indol-3-carbaldehyde thiosemicarbazones: inhibitory activity against fungi and bacteria," Journal of Inorganic Biochemistry, vol. 99, no. 11, pp. 2231-2239, 2005.

[2] T. C. Leboho, J. P. Michael, W. A. L. van Otterlo, S. F. van Vuuren, and C. B. de Koning, "The synthesis of 2- and 3-aryl indoles and 1,3,4,5-tetrahydropyrano[4,3-b]indoles and their antibacterial and antifungal activity," Bioorganic and Medicinal Chemistry Letters, vol. 19, no. 17, pp. 4948-4951, 2009.

[3] R. C. Larock and E. K. Yum, "Synthesis of via pallailumcatalyzed heteroannulation of internal alkynes," Journal of the American Chemical Society, vol. 113, no. 17, pp. 6689-6690, 1991.

[4] S.-L. Cui, J. Wang, and Y.-G. Wang, "Synthesis of indoles via domino reaction of $\mathrm{N}$-Aryl amides and ethyl diazoacetate," Journal of the American Chemical Society, vol. 130, no. 41, pp. 13526-13527, 2008.

[5] M. C. Fagnola, I. Candiani, G. Visentin et al., "Solid-phase synthesis of indoles using the palladium-catalysed coupling of alkynes with iodoaniline derivatives," Tetrahedron Letters, vol. 38, no. 13, pp. 2307-2310, 1997.

[6] D. Lee, C. Cho, J. Kim, Y. Youn, S. Shim, and H. Song, "Ruthenium complex-catalyzed synthesis of indoles from $N$-substituted anilines and alkanolamines," Bulletin of the Korean Chemical Society, vol. 17, pp. 1132-1135, 1996.

[7] A. Yasuhara, Y. Kanamori, M. Kancko, A. Numata, Y. Kondo, and T. Sakamoto, "Convenient synthesis of 2-substituted indoles from 2-ethynylanilines with tetrabutylammonium fluoride," Journal of the Chemical Society-Perkin Transactions 1, no. 4, pp. 529-534, 1999.

[8] R. Haugland, J. Yguerabide, and L. Stryer, "Dependence of the kinetics of singlet-singlet energy transfer on spectral overlap," Proceedings of the National Academy of Science, vol. 63, no. 1, pp. 23-30, 1969.

[9] R. Haugland, J. Yguerabide, and L. Stryer, "Dependence of the kinetics of singlet-singlet energy transfer on spectral overlap," Proceedings of the National Academy of Sciences of the United States of America, vol. 63, no. 1, pp. 23-30, 1969.

[10] V. M. Moreira, J. A. R. Salvador, A. M. Beja, and J. A. Paixão, "The reaction of azoles with 17-chloro-16-formylandrosta5,16-dien-3 $\beta$-yl-acetate: synthesis and structural elucidation of novel 16-azolylmethylene-17- oxoandrostanes," Steroids, vol. 76, no. 6, pp. 582-587, 2011.

[11] V. M. A. Moreira, T. S. Vasaitis, V. C. O. Njar, and J. A. R. Salvador, "Synthesis and evaluation of novel 17-indazole androstene derivatives designed as CYP17 inhibitors," Steroids, vol. 72, no. 14, pp. 939-948, 2007.

[12] J. Samu, J. Botyanszki, H. Duddeck, G. Snatzke, and I. Cholesteno-Indole, "Synthese von 1'H-5 $\alpha$-Cholest-2-eno[3, 2b]indolen," Liebig's Annalen der Chemie, vol. 11, pp. 1225-1227, 1993.

[13] L. Figueroa-Valverde, F. Díaz-Cedillo, and E. García-Cervera, "A facile synthesis of an indol-dihydrotestosterone succinate derivative," Bulgarian Chemical Communications, vol. 44, no. 1, pp. 83-86, 2012.

[14] J. R. Beck, "Nucleophilic displacement of aromatic nitro groups," Tetrahedron, vol. 34, no. 14, pp. 2057-2068, 1978.

[15] T. Takekoshi, J. G. Wirth, D. R. Heath, J. E. Kochanowski, J. S. Manello, and M. J. Webber, "Polymer syntheses via aromatic nitro displacement reaction," Journal of Polymer Science, vol. 18, no. 10, pp. 3069-3080, 1980.

[16] E. J. Corey and A. Venkateswarlu, "Protection of hydroxyl groups as tert-butyldimethylsilyl derivatives," Journal of the American Chemical Society, vol. 94, no. 17, pp. 6190-6191, 1972.

[17] R. F. Newton, D. P. Reynolds, M. A. W. Finch, D. R. Kelly, and S. M. Roberts, "An excellent reagent for the removal of the tbutyldimethylsilyl protecting group," Tetrahedron Letters, vol. 20, no. 41, pp. 3981-3982, 1979.

[18] X. Xu, D. Cheng, J. Li, H. Guo, and J. Yan, "Copper-catalyzed highly efficient multicomponent reactions: synthesis of 2(sulfonylimino)-4-(alkylimino)azetidine derivatives," Organic Letters, vol. 9, no. 8, pp. 1585-1587, 2007. 

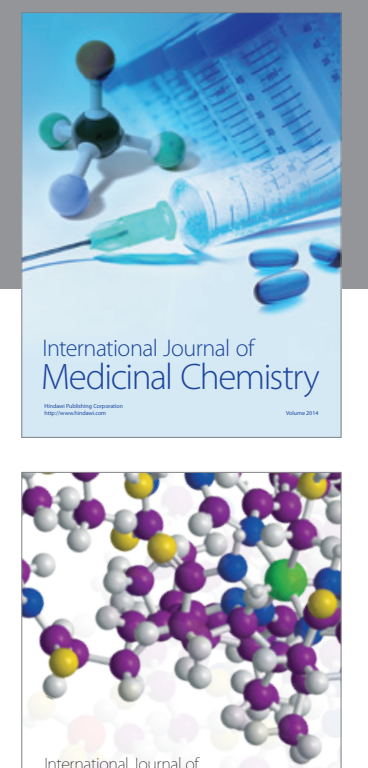

\section{Carbohydrate} Chemistry

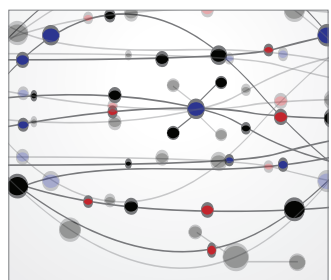

The Scientific World Journal
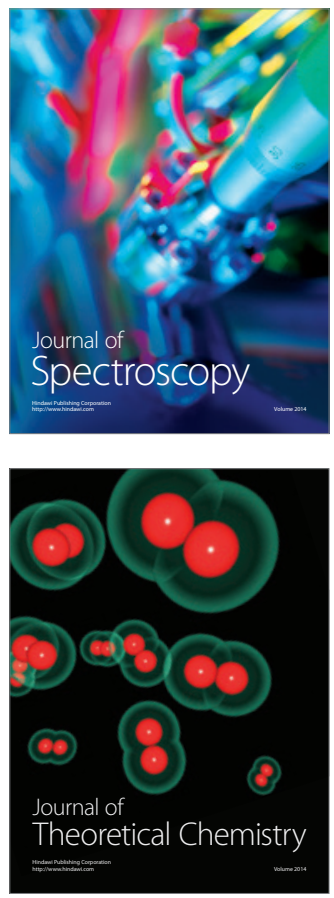
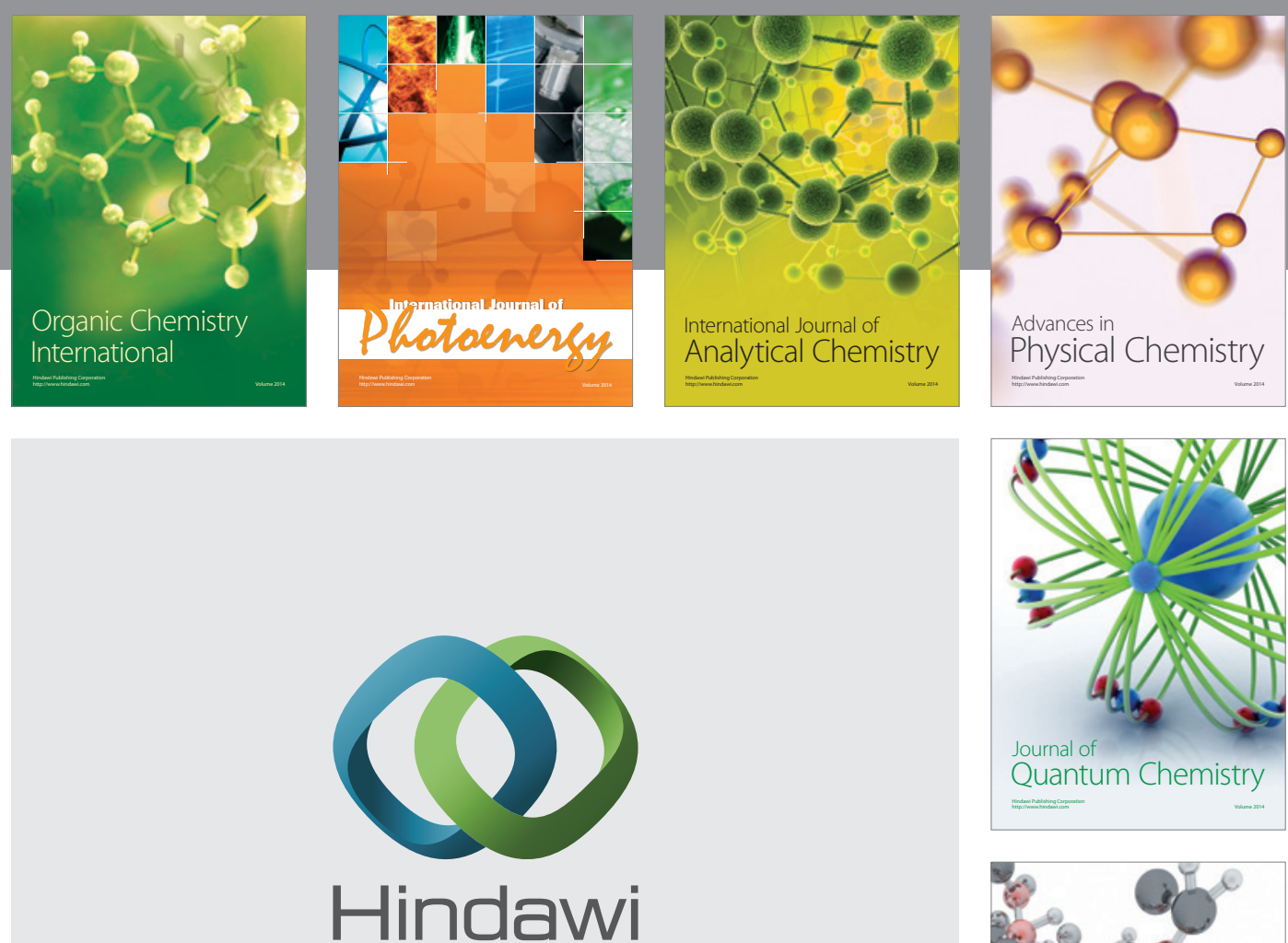

Submit your manuscripts at

http://www.hindawi.com

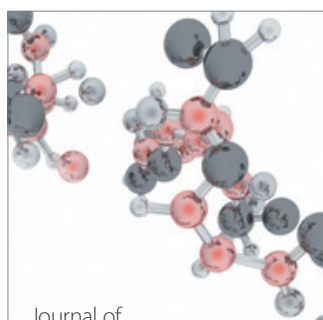

Analytical Methods

in Chemistry

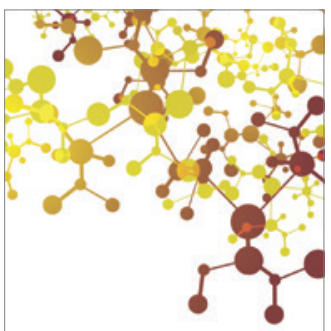

Journal of

Applied Chemistry

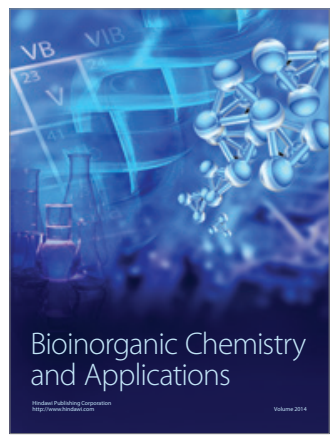

Inorganic Chemistry
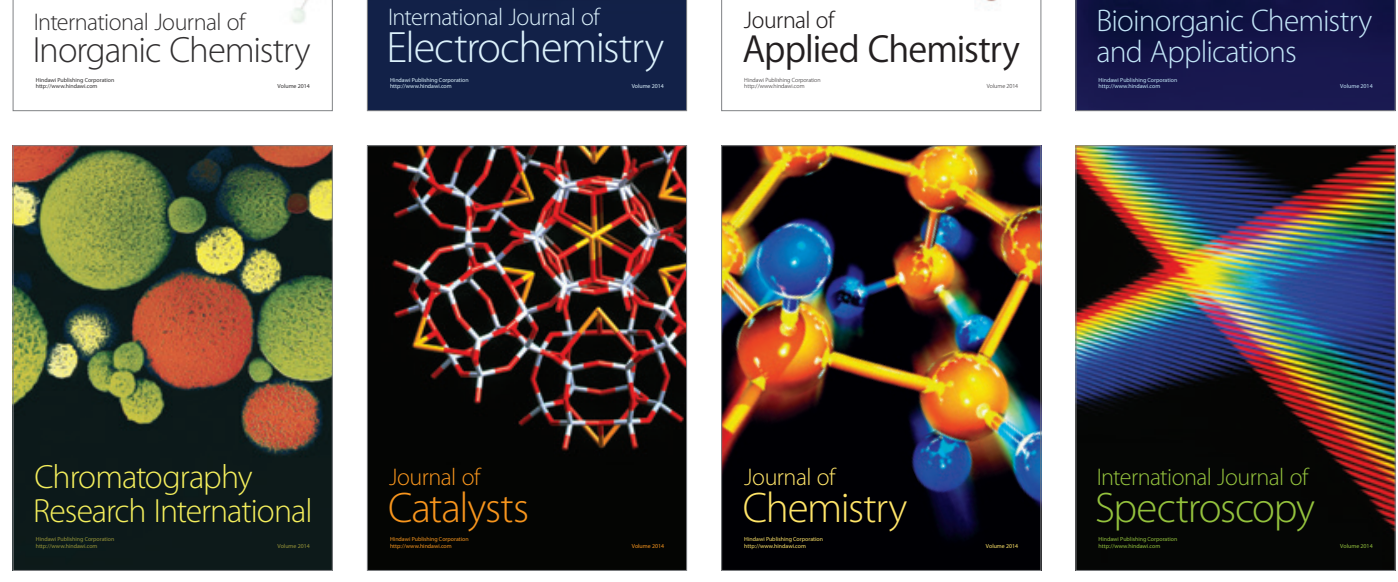